\title{
Translator Behavior Criticism---Ten Years in China
}

\section{Binghui Li}

School of English Language, Literature and Culture, Beijing International Studies University, Beijing, China

\author{
Email address: \\ lbhcathy@163.com
}

\section{To cite this article:}

Binghui Li. Translator Behavior Criticism---Ten Years in China. International Journal of Applied Linguistics and Translation. Vol. 6, No. 1, 2020, pp. 24-28. doi: 10.11648/j.ijalt.20200601.14

Received: February 12, 2020; Accepted: February 27, 2020; Published: March 10, 2020

\begin{abstract}
Translator behavior criticism theory is regarded as one of the main current translation studies theory in China. It is proposed by Professor Zhou Lingshun in 2010 and now it has been for 10 years. In 2014, he made his proposals clearly in two of his influential books. After that, this theory has drawn a lot of attention from the academic circle and the number of related articles on it is increasing year by year. This article starts from changes of the role of translator and translator's position as the center, which provides the background for this theory. Then it moves on to make clear the main proposals and practice of this theory, especially his "truth-seeking and utility attaining" continuum mode of evaluation. Through this continuum mode, one can measure the degree of rationality of a translator's behavior by taking various factors into consideration, and then the evaluation of the translated version. This theory provides a new perspective on translation by combining translator's behavior with translation. But in practice, some scholars also questioned the manipulability of his continuum mode. So in the end, this article talks about the significance and limitations of this theory. His theory is a breakthrough in translation studies, but still needs to be further polished.
\end{abstract}

Keywords: Translator Behavior Criticism, Truth-seeking, Utility-attaining, Cultural Turn, Translator

\section{Introduction}

Translator's behavior criticism theory was put forward by Professor Zhou Lingshun in the year 2010 and now it has been 10 years till now. The author searched on CNKI, the largest and most influential Chinese journal database in China, and found that 81 related articles had been published on various journals from 2010 to 2020. Till Feb. 3, 2020, they have been cited for 709 times and downloaded for 45,155 times, 557.47 times for each article on average, which shows that this theory is popular nowadays in China. Among them, 9 out of the first 12 articles published in the year 2010 and 2011 were written by Professor Zhou himself. They are a series of introductory articles about his theory and criticism of translator behavior. In the year 2014, he published two books: A Theoretical Framework for Translator Behavior Criticism [1], and Approaches to Translator Behavior Criticism [2], which states his theory clearly and has caused heated discussion in China and drew abundant attention from scholars in the field of translation studies. Since then, we have witnessed a rapid increase of relevant articles being published, with 7 in the year 2015; 9 in 2016; 14 in 2017; 9 in 2018 and 15 in 2019. Now this article attempts to make clear the background of his theory, his concrete proposals of theory and practice, the significance and limitations of this theory, and then put forward suggestions for further research.

\section{Background of the Theory}

Translators have been playing a vital role in international cultural communication and contributing a lot to the development of mankind. But their important role was not given enough attention in traditional translation theories. In traditional translation theories, a translation is only a linguistic transfer, inferior to the original text, and translators are invisible servants. "The translator is understood to be a servant, an invisible hand mechanically turning the word of one language into another" [3]. The original text and author were given priority and absolute authority while a translator's act was regarded as mechanical transfer, thus ignoring a translator's subjectivity. Only in recent decades do they draw a lot attention in the field of translation and we have witnessed a gradual transition of attitude towards translators.

Looking back at translation studies in general, we find 
that attitude toward translators can be roughly divided into 3 stages: philological stage; structuralism stage and post-structuralism stage. During the philological stage, or traditional era, the essence of translation studies is pre-scientific with early enthusiasm for freedom in translating [4]. The attitude towards translation is more subjective, laying more emphasis on effect. Since translators have more freedom, translation studies of this stage focuses on translators' function and impact. Then in the structuralism stage, the essence of translation gradually changed to be scientific and the attitude toward translation tended to be more objective. Texts, words and sentences were the focus, and the function and impact of a translator were rarely talked about. But during the post-structuralism stage, the essence of translation now is holistic, and more attention is paid to pragmatic function and macro-context rather than to the text only. One important factor is the cultural turn in humanities. Susan Bassnett and Andre Lefevere urged in the cultural turn in translation studies through their book Translation, History and Culture [5]. Meanwhile we see the flourish of postcolonial translation theory, deconstructionism theory, and feminist translation theory. All of these theories brought translators to the center stage. So as Bassnett said,

"Translation has been redefined in recent years as a form of rewriting, and the status of the translator, once dismissed as little more than a hack, has been revalued"[6]

With this trend, translators became visible, and books or articles on translator sprouted out rapidly. Since the last 1990s for example, book titles with "translator" include Discourse and Translator by Hatim \& Mason [7], The Translator's Turn [8], Professional Issues for Translators and Interpreters [9], The Translator's Invisibility: A History of Translation [10], Translators Through History [11], The Translator Investigated: Learning from Translation Process Analysis [12], Knowledge and Skills in Translator Behavior [13], The Translator as Communicator [14], Who Translate? Translator Subjectivities Beyond Reason [15] and so on. But unfortunately, these books about translators didn't give a systematic and sufficient explanation on translators' role in the translation process. Let's take Hatim and Mason's two books as an example. Although both books have "translator" in their titles and are supposed to talk about translators, but they mainly focuses on discourse. After a general overview on topics in translation studies and influences of linguistics upon translators, the book Discourse and the Translator discusses influences on translation activity from the perspective of semantics, pragmatic, semiology, text type and so on, then emphasizes translator's role only in the end. These two writers tried to promote the idea that a translator is the coordinator and should be in the center of dynamic communication process between the author and target translation readers.

They are not alone. Translation theorists in deconstructionism also tried to highlight translators' role and project their visibility and liberation through dissolving the center position of the author and the original text and reinforce translators' role in understanding, interpreting and manipulating the text. But their focus is still not on translator behavior, nor their position or influence. Actually they did not talk about translator as the center systematically as a theory. Lawrence Venuti, one of the American representatives of deconstructionism, is an influential figure in promoting translator's role. But for both of his important works in the 1990s, Rethinking Translation: Discourse, Subjectivity, Ideology [16] and The Translator's Invisibility: A History of Translation, their notable idea is not about the position of translator, but translating strategies--- foreignization and domestication, even if he demands a greater visibility for translators. Who did foreignization and domestication? Who dominated resistance and subordination? It should be translators. Then why and how they do it? Unfortunately, Venuti didn't make a step further. In all, with the influence of post-colonialism and feminism in translation studies in the past decades, translators were given more freedom and autonomy. Even if they are said to be the center of whole translation process, there is no systematic theory to back it and support it.

After the Opening-up policy in China in 1979, various translation theories flooded to China and scholars in the mainland embraced them eagerly. Chinese scholars gladly introduced and interpreted those western translation theories, from Prague school, London school, communicative theory to cultural turn, post-colonialism, and so on. All these theories have played a very important role in promoting translation studies in China. But after that, the call for a local translation theory echoed in the academic circle of translation studies. It's under this context that translator behavior criticism was created and introduced.

\section{Translator Behavior Criticism Theory and Practice}

In the year 2010, Professor Zhou published his first article about this theory, Translator Behavior and the "Truth-seeking-Utility-attaining" Continuum Mode of Evaluation [17], then he published 10 related articles in the next 2 years. The two books mentioned above published in 2014, which has drawn a lot attention in the academic field in China, indicates that a complete system of translator behavior criticism theory has been established. And the two books were regarded as the main representative work of local translator criticism theory. After that, many scholars have published book reviews and used translator behavior criticism as a tool to do further research on translator behavior.

The translator behavior study is closely related to translator study but they are different. Translator study is centered on the text, and studies the influences upon the text by translators from the perspective of sociology. While translator behavior study takes both the role and behavior of translators and the quality of the text into consideration, focusing on the influences upon the text by the translators' will, identity and the role they play, then using their intersection part to explain translators' behavior. 
Translator behavior criticism is human-oriented, and aims to study both the translator, who has linguistic nature and social nature from the perspective of sociology, and the text produced under the translator's will. With the identity of being a translator, the translator has the linguistic nature and social nature, and his behavior under both natures is still translational behavior. Once the social nature swells and subverts the translator's identity, then his role behavior will go beyond the scope of translation, thus translated version will become non-translation. It's called behavior criticism perspective. From this perspective, one needs to start from a translator's behavior, observe how he manipulates the text, and then measure the degree of rationality of his behavior and the quality of the translated version. It combines the text with factors outside the text, which is a dynamic evaluation.

The main proposal of translator behavior criticism theory is the "truth-seeking---utility-attaining" continuum mode of evaluation. Truth-seeking and utility-attaining are two extremes of a continuum. Truth-seeking is the faithfulness of the translated text to the original text, while utility attaining is the effect of the translated text in society. Truth-seeking is the basis of utility-attaining and they are interchangeable under certain conditions. Truth-seeking is the goal, attitude, method and effect. With this continuum, the evaluation process turns from static to dynamic. As a dynamic continuum of evaluation, translator behavior criticism can be used to evaluate both the translator and translated text. In this continuum, truth-seeking and utility-attaining are two extremes. When the translator tends to be language oriented, the translated text is more loyal to the text and thus more truth-seeking; when the translator is inclined to be a social person, caring about the role he plays in a society, then the translated text is more utility-attaining, and of course, the degree of truth-seeking will be reduced. Then evaluation of both translator behavior and the text contributes to the evaluation of the degree of rationality of a translator's behavior. The lower the truth-seeking level of a translated text, the more deviation of a translator's behavior, but the degree of rationality of a translator's behavior is higher and vice versa. High degree of rationality of a translator's behavior indicates the most possible deviation from truth-seeking. "Truth-seeking" literally and "utility-attaining" practically should not be mutually exclusive. The most reasonable translating behavior should stand on the balance point where takes both factors into consideration.

To translators, truth-seeking and utility-attaining is a dynamic self-disciplined process and they always try to remain balanced between these two extremes, to keep the language and meaning transfer between two languages while not lose their social function, including translators' social goals. Being balanced between these two extremes is the best state for translators, but it's a dynamic process. So sometimes translators may lean towards truth-seeking, which indicates the original text and author, or they may lean towards utility-attaining, which indicates target readers and social acceptance. It's translators' free choice. But these two extremes are indispensable, utility-attaining without truth-seeking towards the text is beyond translation and leads to irresponsible translation. Meanwhile, truth-seeking without utility-attaining is against translator's willpower and denies the social nature of translators and translation, thus it cannot obtain corresponding social effects. The mode can be summarized as the following chart:

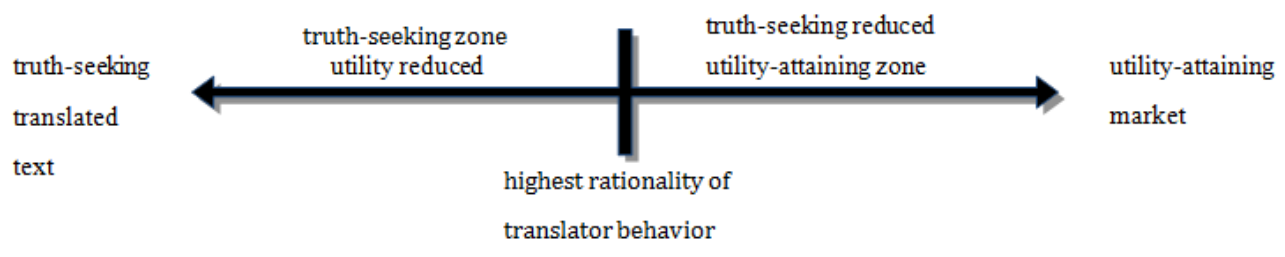

Figure 1. "truth-seeking---utility-attaining” continuum mode of evaluation [18].

In this truth-seeking and utility-attaining evaluation mode, truth-seeking and utility-attaining are spread at the two endpoints of a continuum. When a translator is on this continuum, the translator's behavior shows the degree of truth-seeking and utility-attaining, which constitutes a dynamic continuum. When he leans towards left, it mainly shows his linguistic nature, and when he leans towards right, it shows his social nature, and thus construct a linguistic and social nature continuum of the translator. Since it's a continuum, the translator's position might change on it. All these changes reflect the translator's behavior, attributes and roles, because translators are the subjects and performers of a translation. The changes of the text and translator on the continuum are consistent, because all in all, both of them are influenced by translator's changes in the truth-seeking or utility-seeking zone. The evaluation on the translator's behavior, in some sense, is also the evaluation on the text, because as the manipulator of the text, the translator will inevitably leave some traces in the text. The focus of behavior perspective is the manipulation of the original text and the translated version made by the translator, and the rationality of translator's behavior under social nature as a body of willpower. The more rational his behavior, the more acceptable he is in the society.

The evaluation mode varies based on the differences in translators, text types, and the inner and outer context where 
translators are situated. But only when they are in the reasonable variation permitted by the theory, can one make effective dynamic evaluation on the text and give sound and reasonable explanation to translator's behavior.

For methods employed in this theory, one can describe a translator's behavior; through translator behavior reflected in the text to explain his degree of rationality, and observe the double nature of the translator and the level of his socialized behavior. Then one may reconstruct a stable evaluation mode to dynamically evaluate translators' behavior and the quality of the translated version and apply the reconstructed evaluation mode to practice. Only in practice, one can improve it constantly to make it better. Now many Chinese scholars have used this translator behavior criticism theory to do research on different translation versions of the same text or translation versions of the same period and they have achieved tremendous progress.

Professor Zhou also added details to the evaluation indicators, and proposed three key elements in this bidirectional evaluation system: truth-seeking of the translated version; utility-attaining of effect and degree of rationality of translator behavior. Using these three indicators can not only evaluate the quality of the translated version and the rationality of the translator, but also provides a scientific explanation to some translational phenomenon. That's why this theory is more scientific and more manipulatable. In order to quantify translators' behavior tendency, Professor Zhou provided a scale table.

Table 1. Translator behavior scale table [2].

\begin{tabular}{|c|c|c|c|c|}
\hline \multirow{2}{*}{3 elements } & \multicolumn{2}{|c|}{ translated version } & translator behavior (inner + outer) & \multirow{2}{*}{ subjective evaluation } \\
\hline & 1 truth-seeking & 2 utility-attaining & 3 rationality & \\
\hline \multirow{6}{*}{ scale $(+/-)$} & + & + & + & the best \\
\hline & - & + & + & Better \\
\hline & + & - & + & Better \\
\hline & + & - & - & Worse \\
\hline & - & - & + & Worse \\
\hline & - & - & - & the worst \\
\hline
\end{tabular}

Translator behavior criticism also borrows some mature theories and research methods from sociology and carries out empirical comparative study. One may carry out research on translator behavior by combining objective and subjective factors, translation process and translation result, individual mentality and social psychology, translator behavior both inside and outside the translation. To do the above, they may do interviews, questionnaires, comparative study, correlation study and so on. In this way, one can do a comprehensive research, and give a reasonable description and explanation about a translator's behavior and the quality of the translated version.

\section{Discussion}

The traditional translation criticism tends to regard translation as transfer from one text to another in a static state, so the object of its criticism is confined to translated version, the product of translation, and translating strategies. But this perspective cannot give an objective and comprehensive evaluation of the translated version. Based on this recognition, Professor Zhou focuses on translator behavior, taking translators' linguistic nature and social nature into consideration. By combining behavior's perspective with that of the text, he tries to investigate the relationship between translators' role and the quality of a translated version. With the criticism paradigm of process-subject-behavior-text, his theory gives an objective and comprehensive evaluation of translation, which breaks away from the traditional translation idea of language transfer and text equity, and starts to pay attention to outer factors such as culture, society, history and so on.

The relationship between "Translator Behavior Study" and
"Translator Behavior Criticism" is that of the research field and its theoretical tool. In order to make translator behavior study more descriptive and accountable, a new theoretical perspective is required, thus the theory of translator behavior criticism theory comes into being. Obviously, clarifying their relationship is helpful for the forthcoming researchers to broaden their horizons and deepen their research in this field.

Translator behavior criticism also adds something new to translators' criticism. After cultural turn, translators' life, achievements, translation strategies and such like have been paid much attention. But with translator behavior criticism, translator study is divided into two parts: one is the traditional translator criticism, the other is study on translators' behavior. Actually, translator behavior criticism is the supplement of translator criticism. It refers to translators' social behavior, to see if translators are truth-seeking to the original text and take the need of readers, market or patrons, that is utility attaining, into consideration. It studies a translator's change of role in the process of translation in society as a person and the translated version produced in this context. With this theory, it helps explain such behavior like selective translation, non-orthodox translation, incomplete translation, and such like.

Translators are the subjects and concrete carriers of translation activity and translators' behavior has some regularity to follow. So carrying out research on translator behavior has significance. Translator in the communicative sense is a body of willpower with linguistic nature and social nature, so combining inner translation research with outer translation research can give an objective, comprehensive and reasonable description and explanation to translator behavior and text produced under such behavior. Translator behavior and the text can be evaluated through reconstruction of 
evaluation mode, whose implication can be improved through constant practice. Translator behavior criticism is also closely related to text criticism, on the one hand, the translator's identity and role decide his behavior; on the other, his behavior decides the quality of the translated version. So the quality of a translated version is consistent with the role and identity of the translator. To evaluate the quality of a translated version from the perspective of a translator's identity and role is both comprehensive and objective.

Although Professor Zhou proposed truth-seeking and utility-seeking in the continuum mode of evaluation, he didn't give exact quantification standard to measure them. For example, when talking about the degree of utility-seeking of a translated version, he advised to use ways of doing questionnaires, market research, or software analysis and other ways to get statistics about it. But the statistics only show that this version is better than other versions. We cannot mark it with exact numbers on the continuum mode of evaluation. Hopefully in the future, scholars can settle this problem and find a more manipulatable way.

\section{Conclusion}

The "truth-seeking-utility-attaining" continuum mode of evaluation and the translator behavior criticism proposed by Professor Zhou, which is raised on the basis of the recognition of translator's attributes and the essence of translation, are regard as a breakthrough in the translation studies field and listed among one of the major local translation criticism theories in China. It keeps in line with the cultural turn and the transformation of paradigm from prescriptivism to descriptivism in translation studies as well. The mode can be used as a tool to describe and interpret translator' s behavior and the socialization of translation. By taking the whole translation process into consideration, focus on translator behavior, combine factors outside and inside translation, realize the organic combination of inner criticism with outer criticism, such a translation criticism mode not only deepens understanding on translation and translation criticism, but is a significant and meaningful practice in translation criticism.

Translation criticism is supposed to be both theoretical and practical. Translator behavior criticism creatively proposed a dynamic criticism mechanism, the "truth-seeking-utility-attaining" model of continuum, which enhanced the explanatory power of translation criticism and yet await to be further polished.

\section{Acknowledgements}

This paper is funded by Beijing International Studies University and the project number is 545004/005.

\section{References}

[1] Zhou Lingshun. (2014a) A Theoretical Framework for Translator Behavior Criticism (M). Beijing: The Commercial Press.

[2] Zhou Lingshun. (2014b) Approaches to Translator Behavior Criticism (M). Beijing: The Commercial Press. P. 250.

[3] Godard, Barbara. (1990) 'Theorizing Feminist Discourse/Translation' in Susan Bassnett and Andre Lefevere (eds) Translation, History and Culture, London: Pinter. P. 91.

[4] Nida Eugene A. (1993). Languge, Culture, and transalting (M). Shanghai: Shanghai Foreign Language Education Press.

[5] Bassnett, Susan and Andre Lefevere (eds) (1990) Translation, History and Culture (M), London: Cassell.

[6] Bassnett, Susan (2014) Translation Studies (M). 4th edn, London and New York: Routledge. P. 3.

[7] Hatim, B. and I. Mason. (1990) Discourse and the Translator (M). London/New York: Longman.

[8] Robinson, D. (1991) The Translator's Turn (M). Baltimore: Johns Hopkins University Press.

[9] Hammond, L. (ed.) (1994) Professional Issues for Translators and Interpreters. In American Translators Association Scholarly Monograph Series. Vol. VII (C). Amsterdam/Philadelphia: John Benjamins.

[10] Venuti, Lawrence. (1995) The Translator's Invisibility: A History of Translation (M), London: Routledge.

[11] Delisle, J. \& Woodsworth, J. (eds.) (1995) Translators Through History (M). Amsterdam: Benjamins Publishing Co.

[12] Fraser, J. (1996) The Translator Investigated: Learning from Translation Process Analysis (J). The Translator. (1): 79.

[13] Wilss, W. (1996) Knowledge and Skills in Translator Behavior (M). Amsterdam/Philadelphia: John Benjamins Publishing Company.

[14] Hatim, B. (1997) The Translator as Communicator (M). London and New York: Routledge.

[15] Robinson, D. (2001). Who Translate? Translator Subjectivities Beyond Reason (M). Albany: State University of New York Press.

[16] Venuti, Lawrence. (1992) Rethinking Translation: Discourse, Subjectivity, Ideology (M). London: Routledge.

[17] Zhou Lingshun, (2010) Translator Behavior and the "Truth-Seeking---Utility Attaining" Continuum Mode of Evaluation (J). In Foreign Language Education (1): 93-97.

[18] Shen Jie. (2017). On the Translator Behavior Criticism (J). In Journal of Qiqihar University (8): 127-129. 